\title{
Making Leaders: Leadership Characteristics Of Makers And Engineers In The Maker Community
}

\author{
James Oplinger, Arizona State University, USA \\ Micah Lande, Arizona State University, USA \\ Shawn Jordan, Arizona State University, USA \\ Leonor Camarena, Arizona State University, USA
}

\begin{abstract}
This study examines the emergence of leadership characteristics within a new organizational community of individuals: the Maker community. The Maker community is a group of individuals that classify themselves as "Makers" and have become innovators and entrepreneurs through the creation of technological gadgets, artistic projects, and other end products. Historically, so-called Tinkers were motivated to design and develop objects in their garages apart from other people with similar motivations. Drawing from Quinn's Competing Values Framework, these Maker communities exemplify emergent leadership characteristics within collaboration frameworks. Forty critical incident interviews with Makers express the leadership characteristics of these individuals. Characteristics may differ from individual to another, but a general representation of the community as a whole can be made from observing sub-groups within the community. The results hold important implications for leadership growth, cross-cultural management, and the future for what has become an emerging organizational community. The growth of this community has implications for the field of engineering education and new projectbased learning coursework. The emergence of the Maker community including maker spaces has also become relevant in this context and the future of how we education engineers.
\end{abstract}

Keywords: Maker; Engineering; Competing Values Framework; Leadership

\section{INTRODUCTION}

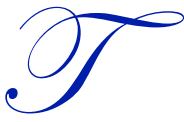

he nature of effective leadership has evolved commensurate with changes in organizations and the environments in which they function (Houghton, Carnes, \& Ellison, 2014). An evolving group of "Makers" in society has developed. Makers are defined as a group of tinkerers, hobbyists, and DIYers who enjoy creating and building technology-facilitated gadgets such as toys (Foster, Dickens, Jordan, \& Lande, 2015), learning new skills, and interacting within a connected community of other self-identified Makers (Dougherty, 2012). Makers have many characteristics that overlap those of engineers (Heiman, Lande, \& Jordan, 2015; Jordan \& Lande, 2014, 2015; Lande, Jordan, \& Nelson, 2013; Oplinger et al., 2014). Maker culture has become a way to express creative drive in a communal setting (Foster, Lande, \& Jordan, 2014; Jordan \& Lande, 2016). This excitement has led to a growth of DIY spaces for creating, inventing, and learning called makerspaces across a range of informal and formal instructional environments. Makerspaces typically include "three interconnected elements: 1. A physical space where people work on and complete Making-related projects and activities; 2. An open community space where exploration, creativity, and collaboration is emphasized; 3 . A multidisciplinary learning experience that seeks to create organic learning experiences for its participants" (American Society for Engineering Education, 2016). Specifically, project-based learning, experimental activities, including libraries, museums, independent nonprofit and for-profit organizations, K-12 schools, and universities (Halverson \& Sheridan, 2014) have been identified as makerspaces available to students at every level. Maker Faire, which began in 2006, has further built upon the growth of Maker culture. Every year members of the Maker community join together at flagship Maker Faire events where they showcase their projects, collaborate with other members, and engage in learning activities (Dougherty, 2012). 
Makers exhibit characteristics of innovation leadership within their community. This study explores leadership within this community of Makers using the Competing Values Framework. The Competing Values Framework for managerial leadership has received renewed attention from organizational researchers and leadership development scholars (Belasen \& Ruger, 2007; Cameron \& Quinn, 2006). Forty adult Makers with experience working with others in the Maker community were interviewed at flagship Maker Faire events in the United States, and the data analyzed to uncover characteristics of leadership that closely align with the competing values framework: innovators, monitors, directors, and producers.

Individuals within this community of Makers are considered individuals within a larger, shared organizational community. Within this context, Makers that have exhibited leadership characteristics have shown an ability to work within a cross-cultural knowledge management approach. Makers have diverse disciplinary backgrounds ranging from art to engineering, and professions from students, to corporate professionals, to entrepreneurs. The purpose of this study is to identify the leadership characteristics that Makers exhibit. To build upon research on the Maker community, an organizational community with little literature surrounding leadership implications, this study analyzes leadership in the Maker community through the use of the Competing Values Framework. Based on the identification of leadership roles and characteristics are expressed by members of the community, engineering educators may emphasize Making within the classroom to teach these leadership characteristics.

\section{THEORY}

\section{Competing Values Framework}

Originated by Quinn and Rohrbaugh (1983) and Quinn (1988), the Competing Values Framework highlights the contrasting nature inherent in organizational environments as well as the complexity of choices faced by managers when they respond to competing tensions (Belasen \& Frank, 2008). The Competing Values Framework allows categorization of leadership roles and expectations (Quinn, Hildebrandt, Rogers, \& Thompson, 1990; Zafft, Adams, \& Matkin, 2009), which is useful to apply in order to better understand the Maker community.

Through multidimensional scaling, Quinn and Rohrbaugh (1983) extracted a circular model of value orientations. There have been validation studies (Buenger, Daft, Conlon, \& Austin, 1996; Hartnell, Ou, \& Kinicki, 2011) and wide application in the areas of organizational behavior (Erdogan, Liden, \& Kraimer, 2006), organizational culture diagnosis and change (Cameron and Quinn, 2011), strategic human resource management (Chan et al., 2004), and management training and development (Belasen \& Frank, 2008; Sendelbach, 1993). See Figure 1 for a representation of Competing Values Framework of leadership roles (Tong \& Arvey, 2015). 
Figure 1. Competing Values Framework of leadership roles (Tong \& Arvey, 2015)

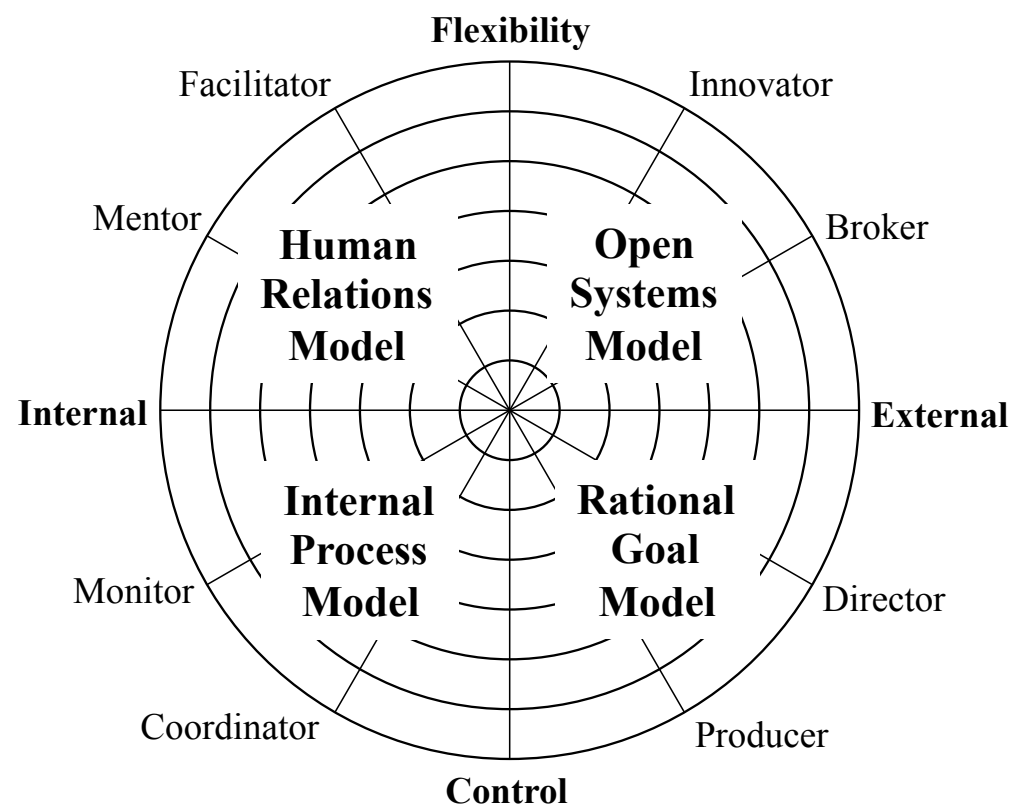

Across the graph are two axes, organizational focus (Internal-External) and adaptability (Control-Flexibility). Each value is considered opposite of the other end of the axis (Zafft et al., 2009). To a similar extent the quadrants opposite of each other represent conflicting values (Quinn, 1988). Table 1 provides a description of each quadrant and leadership role.

Table 1. Leadership quadrants and role descriptions (Zafft et al., 2009)

\begin{tabular}{|c|c|}
\hline $\begin{array}{c}\text { Quadrant and } \\
\text { Management Models }\end{array}$ & Leadership Role \\
\hline $\begin{array}{l}\text { Relating to People } \\
\text { Human Relations Model }\end{array}$ & $\begin{array}{l}\text { - Mentor: Acknowledges personal needs, develops people, caring, empathetic. } \\
\text { - Facilitator: Practices participation and teambuilding, focuses on consensus building, manages } \\
\text { conflict and encourages participative decision-making. } \\
\text { - Internally-focused and flexible; emphasizes participation, conflict resolution, and consensus } \\
\text { building (Quinn et al., 1990) }\end{array}$ \\
\hline $\begin{array}{l}\text { Leading Change } \\
\text { Open Systems Model }\end{array}$ & $\begin{array}{l}\text { Innovator: Inspires, anticipates customer needs, initiates significant changes, new ideas, } \\
\text { experiments, problem solves, adaptable. } \\
\text { - Broker: Sells ideas, influences decisions at higher levels, acquires needed resources, strong } \\
\text { negotiator. } \\
\text { - Externally-focused and flexible; emphasizes adaptation (Quinn et al., 1990) }\end{array}$ \\
\hline $\begin{array}{l}\text { Producing Results } \\
\text { Rational Goals Model }\end{array}$ & $\begin{array}{l}\text { Producer: Focuses on outside competition, emphasizes speed, hard work ethic, motivates } \\
\text { people, initiates action. } \\
\text { - Director: Provides clear direction, clarifies priorities, communicates the vision, plans and } \\
\text { prioritizes. } \\
\text { - Internally-focused and controlled; emphasizes goal clarification, rational analysis of problems, } \\
\text { and taking action (Quinn et al., 1990) }\end{array}$ \\
\hline $\begin{array}{l}\text { Managing Processes } \\
\text { Internal Process Model }\end{array}$ & $\begin{array}{l}\text { Monitor: Clarifies policies, expects accurate work, controls projects, monitors progress, } \\
\text { develops measures and checkpoints. } \\
\text { - Coordinator: Brings order, plans schedules, provides stability, control and continuity. } \\
\text { - Internally-focused and controlled; emphasizes the definition of responsibilities, measuring } \\
\text { results, and documenting characteristics (Quinn et al., 1990) }\end{array}$ \\
\hline
\end{tabular}




\section{The Human Relations Model}

Individuals that fall within this quadrant are identified as a mentor and a facilitator. Leaders characterized by the human relations model engage team members through conflict resolution and consensus building (Quinn et al., 1990). Leaders within the human relations roles develop interaction and comaraderie among the group (Quinn, 1988; Yang, 2007). As a mentor, leaders understand themselves and those around them, provides a source of communication, and develops others. As a facilitator, they add to team building, encourage participative decision making, and manage conflicts.

\section{The Open Systems Model}

Those that fall within this quadrant are identified as innovators and brokers. The open systems model requires leaders to partake in an ambiguous and competitive environment (Quinn et al., 1990). Leaders within the open systems roles are considered idealistic, absorbing and collecting new information (Quinn et al., 1990; Yang, 2007). As an innovator, a manager is keeping up with growth, thinking creatively, and directing change. As a broker, they build and maintain resources, negotiate with others, and are involved in the exchanging of ideas.

\section{The Rational Goals Model}

This quadrant identifies leaders as producers and directors. Leaders characterized by the rational goals model believe that a "clear direction leads to productive outcomes" (Quinn et al., 1990). Leaders within the rational goal model focus on the direction of the project. As a producer, one must have personal initiative, motivate others, and manage stress and time. As a director, managers have to take initiative, set goals, and delegate effectively.

\section{The Internal Process Model}

Leaders within the internal process roles are considered responsible and accountable (Yang, 2007) (Cameron, Quinn, DeGraff, \& Thakor, 2014). As a monitor, managers organize information, evaluate reports, and respond to results. Leaders in this role are responsible for maintaining rules and providing review (Yang, 2007). As a coordinator, a leader creates plans, organizes the team, and controls production. They "simplify routines and build up good relations with other parties" (Yang, 2007). Leaders within these roles are often experts or organizers (Cameron et al., 2014).

\section{Utilizing the Competing Values Framework}

To understand an analysis using the Competing Values Framework, Quinn (1988) provides an example analysis of a high-tech firm. In his experiment, Quinn's group consulted with executives of the company during a retreat in order to profile the organization on a spider graph (see Figure 2). The profile ranges intensity in the representation of each leadership role from -3 to 3 . In this profile, 0 operates as an "average" representation among leaders. Traits that are weakly expressed — or not expressed at all — are negative in value. Traits that are highly expressed among the company executives are above the 0 mark. 
Figure 2. Profile of a High-Tech Firm (Quinn, 1988)

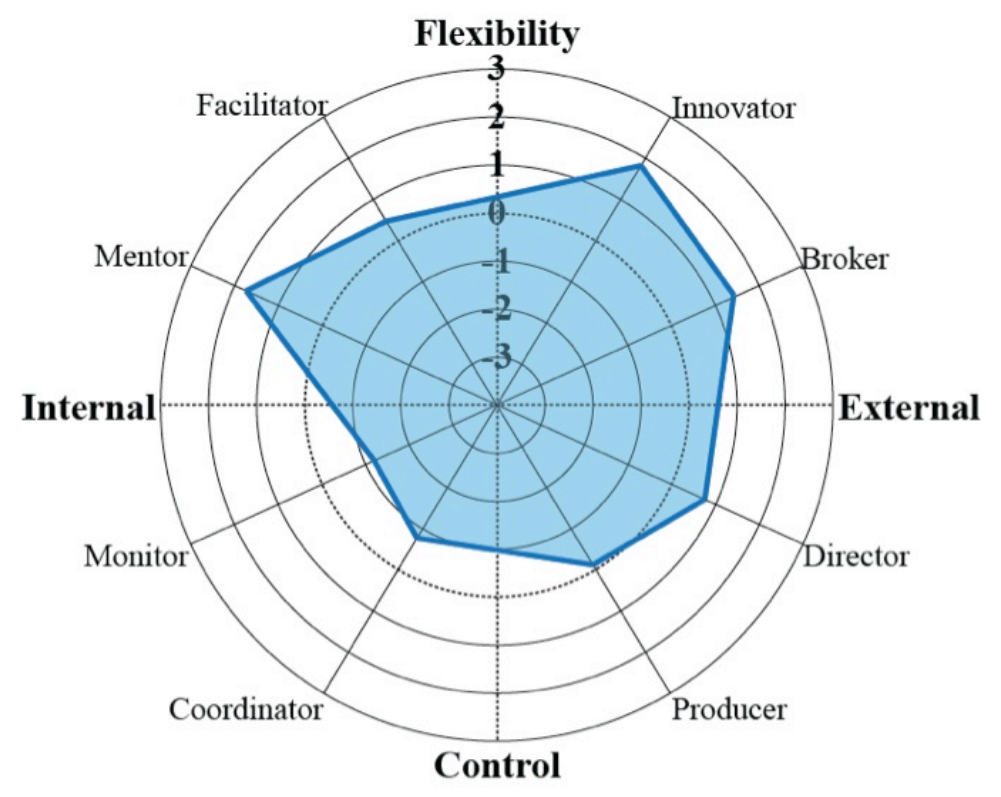

As can be seen from Figure 2, the example of the company shows that the executives in the group excel in open systems and their ability to innovate, adapt, and acquire resources. On the opposite end, the company ranks lower in its internal processes. Quinn (1988) notes that the executives agreed documentation and sharing of verbal information needed to increase. From this diagnosis, the company is able to reevaluate how it operates and make improvements where necessary.

\section{Organizational Leadership}

Schein (1992) provides a definition of organizational culture that integrates both the ideational and materialist components of culture and is general enough in its wording to allow for elements of differentiation:

A pattern of shared basic assumptions that the group learned as it solved its problems of external adaption and internal integration that has worked well enough to be considered valid and, therefore, to be taught to new members as the correct way to perceive, think, and feel in relation to these problems (p. 12).

Makers operate in collaborative spaces where they share experiences and information (Dougherty, 2012; Foster et al., 2014). These spaces range from community makerspaces and hackerspaces (Tweney, 2009) to commercial spaces like TechShop (TechShop, 2015). These spaces allow Makers to learn from each other and build upon one another's experiences. Typically, Making is not a solo-activity (Foster et al., 2014) because of its community reference. The community, or rather organization, of Makers has allowed diverse individuals to work with one another with ideas and materials to contribute to the world of designing and making. Academics lack consensus on a precise definition of culture (Frontiera, 2010), but organizational culture in simple terms can be described as "the way we do things around here" or the values that hold an organization together (Frontiera, 2010). The Maker community offers a broad spectrum of individuals engaged in informal engineering and tinkering activities across multiple pathways (Foster, Wigner, Lande, \& Jordan, 2015). Pathways such as schooling within STEM (science, technology, engineering and math) subjects, other development of technical skills or a hobby in making have led the Makers to evolve into an organization or individuals that work within the same affinity group.

Schein $(1990,1992)$ defines three levels of organizational culture by way of artifacts, values and underlying assumptions. The first level is composed of the artifacts that an organization makes public, such as a vision statement or a physical location. These spaces can consist of museums, schools, and makerspaces and they all 
exhibit an interest in promoting the value of making. The second level of culture is the values, how are they reflected in how the members interact with one another, how do members interact with their environment, and what constructs, such as honesty, integrity or profitability, members share (Schein, 1992). These values or characteristics within the organization of Makers to develop and create innovative things are a central focus. The third level of organizational culture, and the deepest, consists of the underlying assumptions. Identification and articulation of these assumptions provides a basis for describing the values of an organization (Frontiera, 2010). By studying where Makers lie on a research spectrum, the ability of the Maker community to work and operate analogous to the operations of an organization's leaders, visions, and values will be revealed.

Makers range in expertise from novice to experts, each sharing an enthusiasm for building, creation and invention. These varying levels of experience and interest allow for the ability for these groups of individuals to interact within a larger organizational culture context. The values and norms inherent in a culture assist in shaping individual behavior, and resulting culture may increase individual commitment (Frontiera, 2010).

\section{METHODS}

Building on the Competing Values Framework approach for leadership, this study attempts to highlight the leadership roles, skills and behaviors which are associated within the Maker community as either a producer, director, facilitator, innovator or broker.

\section{Sample and Demographic Characteristics}

The study relied upon critical incident and artifact elicitation interviews (Douglas, Jordan, Lande, \& Bumbaco, 2015) conducted with 40 adult Makers exhibiting at four flagship Maker Faires in the United States. Artifact elicitation interviews, based on the method of photo elicitation (Harper, 2002; Morley, Pawley, Jordan, \& Adams, 2011), were conducted with the Makers in front of their exhibits. Makers were asked to describe their invention, including how it works and their process for bringing the idea to fruition. These in-person interviews help explore the knowledge, skills and attitudes of the Makers. Additional information on the research methods can be found in Lande \& Jordan (2014).

Participants were identified through a screening questionnaire. A stratified purposeful sampling strategy was used to select participants. The primary strata for selecting participants were their self-identification as a Maker, level of formal engineering education experience, level of informal engineering education experience, ethnicity, and gender. The secondary strata for selection of participants were whether they had an engineering-related career or hobby, years of experience as a Maker, and age. Forty (40) adult Makers participated in this study. Twenty-three (23) were male; seventeen (17) were female. The majority of participants identified as being a Maker for at least 5 years (23 participants), with ten of them being Makers for over 10 years. In addition, the majority of participants identified as having an engineering-related job/career (22 participants).

\section{Instruments}

Artifact elicitation interviews were conducted with the 40 participants in front of their exhibits at the Maker Faire festivals. These interviews were audio and video-recorded, transcribed, and later analyzed using NVivo qualitative coding software. The interview protocol relied on the physical artifact that the Maker created and brought to the festival. Participants were asked to describe the product and process behind the artifact, as well as any collaboration of the team involved. Table 2 shows sample questions that were asked in the interviews. These questions focused on the knowledge, skills, and attitudes of the Makers. 
Table 2. Sample artifact elicitation interview questions

\begin{tabular}{l|l}
\hline Can you tell me a little bit about what you brought to Maker Faire? & Knowledge, Skills \\
\hline What (knowledge and skills) did you have to learn to make this invention? & Knowledge, Skills \\
\hline What is your process for designing your invention? & \\
\hline Who do you do your Making with? & Attitudes, Skills, Knowledge \\
\hline How did you come up with the idea for this invention? & Attitudes \\
\hline What is the next thing you're going to make, and why? & Lifelong Learning \\
\hline
\end{tabular}

\section{Leadership Measurement}

In order to assess leadership traits within the Maker community a researcher utilized the descriptions of each role in Table 1. The questionnaire in Figure 3 was utilized to exemplify the leadership roles. The interviews were then analyzed to determine if there were any emergent leadership characteristics that matched the leadership roles that were listed in Figure 3.

Figure 3. Leadership Assessment Questionnaire, based upon the Competing Values Leadership Instrument: The View of Others (Quinn, 1988)

\begin{tabular}{|l|}
\hline In their Making, this person: \\
1. Listens to the problems of team members/subordinates. (Mentor) \\
2. Reviews and/or reflects upon project achievements. (Monitor) \\
3. Influences decisions made at higher levels. (Broker) \\
4. Does problem solving in creative, clever ways. (Innovator) \\
5. Clearly defines areas of responsibility for team members/subordinates. (Director) \\
6. Displays a wholehearted commitment to the job/project. (Producer) \\
7. Facilitates consensus building in work-group sessions. (Facilitator) \\
8. Protects continuity in day-to-day operations. (Coordinator) \\
9. Compares records, reports, and so on to detect any discrepancies in them. (Monitor) \\
10. Shows empathy and concern in dealing with others. (Mentor) \\
11. Sets clear objectives for the project and/or team/work unit. (Director) \\
12. Searches for innovations and potential improvements. (Innovator) \\
13. Works on maintaining a network of influential contacts. (Broker) \\
14. Insists on minimum disruption to the work flow. (Coordinator) \\
15. Reflects high motivation for the role. (Producer) \\
16. Encourages participative decision making in work-group sessions. (Facilitator)
\end{tabular}

In order to develop a concise way in which to categorize the responses from Figure 3 even further, a method was developed in which the phrasing would designate certain leadership characteristics.

In analyzing the critical incident and artifact elicit interviews and comparing the Leadership Assessment Questionnaire (Figure 3), we were able to analyze the emergent leadership characteristics of the individual Makers. Phrases from the interviews with Makers produced the ability to trace a path by following the content of their creation and tracing their role in the process back to the Competing Values Leadership Instrument. This engagement property of content from these interviews allowed a deeper insight into the social complexities of the leadership qualities within this community. Interviews allowed insight into the collaboration techniques of individuals that worked with one another, and they allowed an explanation of how individuals viewed their roles and responsibilities within organizational collaboration.

From the Competing Values Framework, a coding scheme was developed to represent each leadership role. Utilizing NVivo (Bazeley \& Richards, 2000), each instance of the nodes was coded when the interviewee expressed a leadership role. Figure 4 provides an example excerpt of an interview code. A similar process was done for each artifact elicitation interview transcript. 
Figure 4. Example coding of an artifact elicitation interview.

BA_2014_404: Well so we were trying to create, we initially created it for burning man and we're trying to create sort of a roadside element that was interactive and large scale but all of the three of us who made it are all dads and new dads so we didn't have a lot of time.

I: Yeah.

BA_2014_404: So we wanted simplicity and then it just sort of came to me the Unnecessarily High Five and that the hands sort of got progressively higher and we put it together...

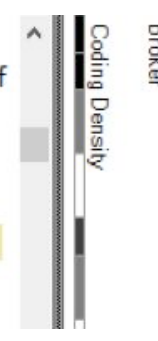

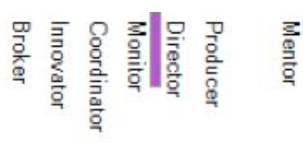

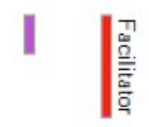

Each highlighted instance of a node represents when a Maker expressed a trait like those described in Figure 3. For example, "So we [the Maker's team] wanted simplicity," closely represents the Maker setting a clear objective for the team, which closely matches that of a director role. In another example, "it just sort of came to me," is a moment where the Maker shows the process behind consensus building, a trait of that closely fits the facilitator role. After completing analysis of each individual Maker a matrix of each Maker's representation of each role was exported (see example matrix, Table 3). This allowed for a direct comparison of each Maker.

Table 3. Example matrix exported from NVivo

\begin{tabular}{l|c|c|c|c|c|c|c|c|}
\hline & Broker & Innovator & Coordinator & Monitor & Director & Producer & Facilitator & Mentor \\
\hline Samantha & 2 & 3 & 0 & 3 & 2 & 2 \\
\hline Aaron & 1 & 1 & 0 & 2 & 2 & 0 \\
\hline Eric & 1 & 2 & 1 & 3 & 0 & 0 \\
\hline Scott & 1 & 1 & 1 & 0 & 1 & 0 \\
\hline Brittany & 2 & 1 & 1 & 1 & 2 & 0 \\
\hline Stephanie & 1 & 0 & 0 & 2 & 3 & 0 \\
\hline Travis & 1 & 0 & 0 & 2 & 1 & 0 \\
\hline
\end{tabular}

The highest number in each matrix row was used to map each participant to a Competing Values Framework profile. Each participant was then given a rank from -3 to 3 based upon how frequently they expressed the leadership roles. The 0 mark acted as an average expression mark.

\section{RESULTS: PROFILED MAKERS}

For this study the 40 Makers were profiled on a leadership spectrum using the Competing Values Framework. These Makers came from four flagship Maker Faires. From the collected data the frequency of responses was mapped across the Competing Values Framework spectrum. The Competing Values Framework utilizes scores between -3 and 3. An average of representation of the trait among Makers was taken in order to determine the 0 - or average representation-mark. A minimum value (-3) shows that the Maker did not represent the leadership trait. A maximum value (3) shows that the Maker represented the highest frequency of trait representation. These minimum and maximum values were used in combination with the data matrices to determine the leadership role representation. Table 4 provides the ranks of each Maker observed on the leadership spectrum. Pseudonyms have been assigned for these Makers' identities. 
Table 4. Makers' ranks on the leadership spectrum

\begin{tabular}{|c|c|c|c|c|c|c|c|c|}
\hline & Broker & Innovator & Coordinator & Monitor & Director & Producer & Facilitator & Mentor \\
\hline Samantha & 0.5 & 2.3 & -3 & 1.2 & 0.5 & 0.5 & -0.5 & -3 \\
\hline Aaron & -0.5 & -0.5 & -3 & 0.5 & 0.5 & 0.5 & -3 & -3 \\
\hline Eric & -0.5 & 0.5 & -0.5 & 1.2 & -3 & -3 & -3 & -3 \\
\hline Scott & -0.5 & -0.5 & -0.5 & -3 & -0.5 & -0.5 & -3 & -3 \\
\hline Brittany & 0.5 & -0.5 & -0.5 & -0.5 & 0.5 & -3 & -3 & -3 \\
\hline Stephanie & -0.5 & -3 & -3 & 0.5 & 1.2 & 0.5 & -0.5 & -3 \\
\hline Travis & -0.5 & -3 & -3 & 0.5 & -0.5 & -3 & -3 & 0.5 \\
\hline Charley & -3 & -0.5 & -3 & 1.2 & 2.3 & -0.5 & -3 & -3 \\
\hline Nick & 1.2 & 0.5 & -3 & 0.5 & 2 & -0.5 & -3 & -0.5 \\
\hline Cane & 1.2 & 1.6 & -3 & 2.3 & 0.5 & -0.5 & -3 & -3 \\
\hline Matt & -3 & 1.6 & -3 & -3 & 2 & 1.2 & -3 & -3 \\
\hline Max & -0.5 & -0.5 & -3 & 2.3 & 2.3 & -0.5 & -3 & -0.5 \\
\hline Mark & -3 & 1.2 & -3 & -0.5 & 2 & 1.6 & -3 & 0.5 \\
\hline Roberto & -3 & 0.5 & -3 & -0.5 & -0.5 & -0.5 & -3 & -3 \\
\hline Alex & -3 & 0.5 & -0.5 & 1.2 & -0.5 & -0.5 & -3 & -3 \\
\hline Carlos & 0.5 & 1.6 & -3 & 2.5 & 1.2 & 0.5 & -3 & -0.5 \\
\hline Shay & 1.6 & 1.2 & -3 & 1.6 & -0.5 & 0.5 & -0.5 & -0.5 \\
\hline Julia & -0.5 & 0.5 & -0.5 & 0.5 & 1.2 & -3 & -3 & -3 \\
\hline Richard & 0.5 & 1.6 & -3 & 1.2 & 0.5 & -0.5 & -3 & -3 \\
\hline Pam & -3 & -3 & -3 & 2 & -3 & 2 & -3 & 1.2 \\
\hline Ray & -3 & 1.6 & -3 & 1.2 & 1.6 & -0.5 & -0.5 & -3 \\
\hline Ruben & -0.5 & 2 & -3 & 2.3 & 2.5 & 1.2 & -3 & -3 \\
\hline Stephen & 2 & 0.5 & -3 & 0.5 & 2.3 & 2.5 & -3 & -3 \\
\hline Rebecca & -0.5 & 0.5 & -3 & -3 & 0.5 & 0.5 & -3 & -3 \\
\hline Heather & -3 & -3 & -3 & 2 & 2.5 & -0.5 & 2 & 1.2 \\
\hline Riya & -3 & 1.6 & -3 & 0.5 & 2.5 & 0.5 & -0.5 & -3 \\
\hline Jason & 1.6 & 2 & -3 & 3 & 0.5 & 0.5 & -0.5 & -3 \\
\hline Jessica & -3 & -3 & -0.5 & -0.5 & 1.2 & -0.5 & -3 & -3 \\
\hline Stan & -0.5 & -0.5 & -3 & -0.4 & 0.5 & 0.5 & -0.5 & -3 \\
\hline Yin & -0.5 & -0.5 & -3 & 0.5 & 2.9 & -0.4 & -3 & -3 \\
\hline Jack & -0.5 & 0.5 & -3 & 1.2 & 2.3 & 0.5 & 0.5 & -3 \\
\hline Cindy & -0.5 & -0.5 & -0.5 & 0.5 & 0.5 & -0.5 & -3 & -3 \\
\hline Mia & 1.2 & 0.5 & -3 & 1.6 & 0.5 & 0.5 & -3 & -3 \\
\hline Andrew & -0.5 & -0.5 & -3 & 1.2 & 1.2 & -3 & -3 & -3 \\
\hline Rachel & -3 & -0.5 & -3 & -0.5 & 0.5 & -0.5 & -3 & -3 \\
\hline Kelsey & -0.5 & -3 & -3 & -0.5 & 1.2 & -3 & -3 & -3 \\
\hline Wanda & -0.5 & -0.5 & -3 & -0.5 & 1.6 & 0.5 & -3 & 0.5 \\
\hline Jenna & 1.6 & 1.6 & -0.5 & 1.2 & 2.3 & 1.2 & -3 & -3 \\
\hline Ronald & 1.2 & 1.2 & -3 & 2 & 0.5 & -3 & -3 & -3 \\
\hline David & -3 & 0.5 & -0.5 & 1.2 & 1.6 & -3 & -3 & -3 \\
\hline
\end{tabular}

Once the Makers were ranked, Critical Values Framework graphs were plotted on a spider chart to provide a visual representation. An average of leadership ranks for each trait was taken in order to provide a representation of the observed Maker community. Figure 5 shows the resulting graph of the Maker community. 
Figure 5. Profile of the Maker community as derived from profiles of 40 Makers

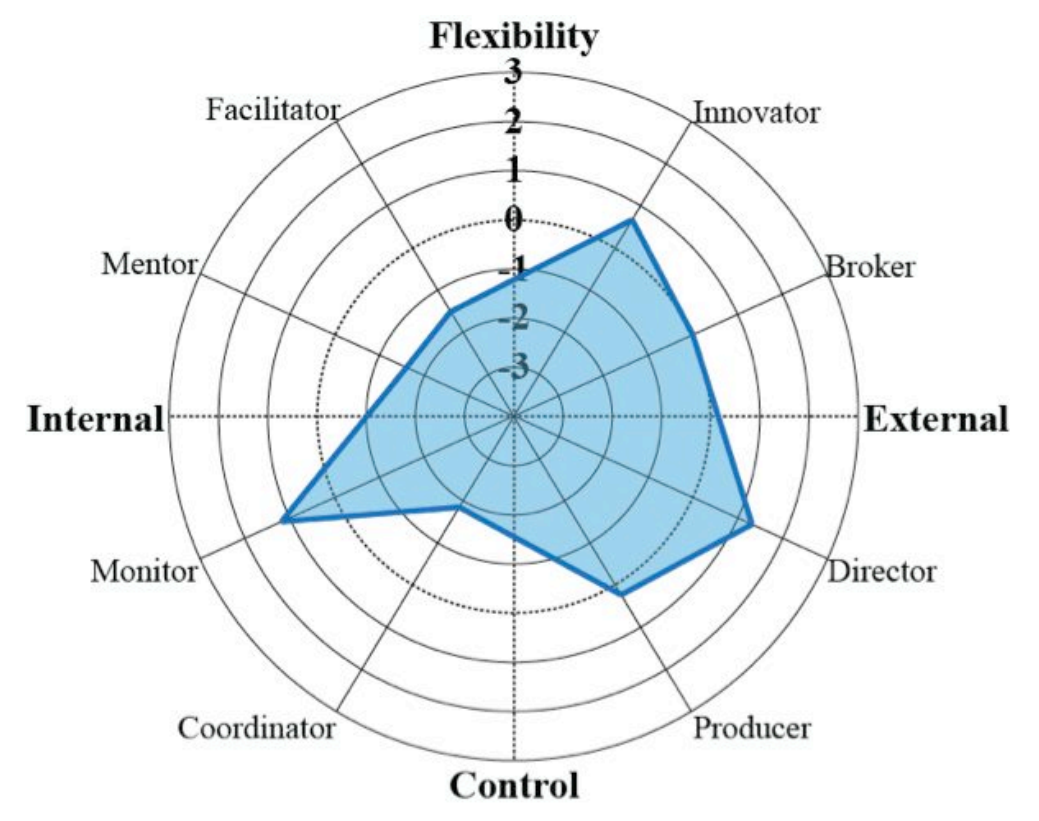

As can be seen in Figure 5, Makers express innovator, director, producer, and monitor leadership roles above all others. This implies that Makers hold a high aptitude in external leadership roles, while also maintaining the ability to review and analyze results. In order to see what graphs of individual Makers look like, plots were made for the top innovator, director, producer, and monitor among the observed Makers (Figures 6). 
Figure 6 Profiles of the top innovator (Samantha, top-left), director (Yin, top-right), producer (Stephen, bottom-left), and monitor (Trisha, bottom-right) among the observed Makers
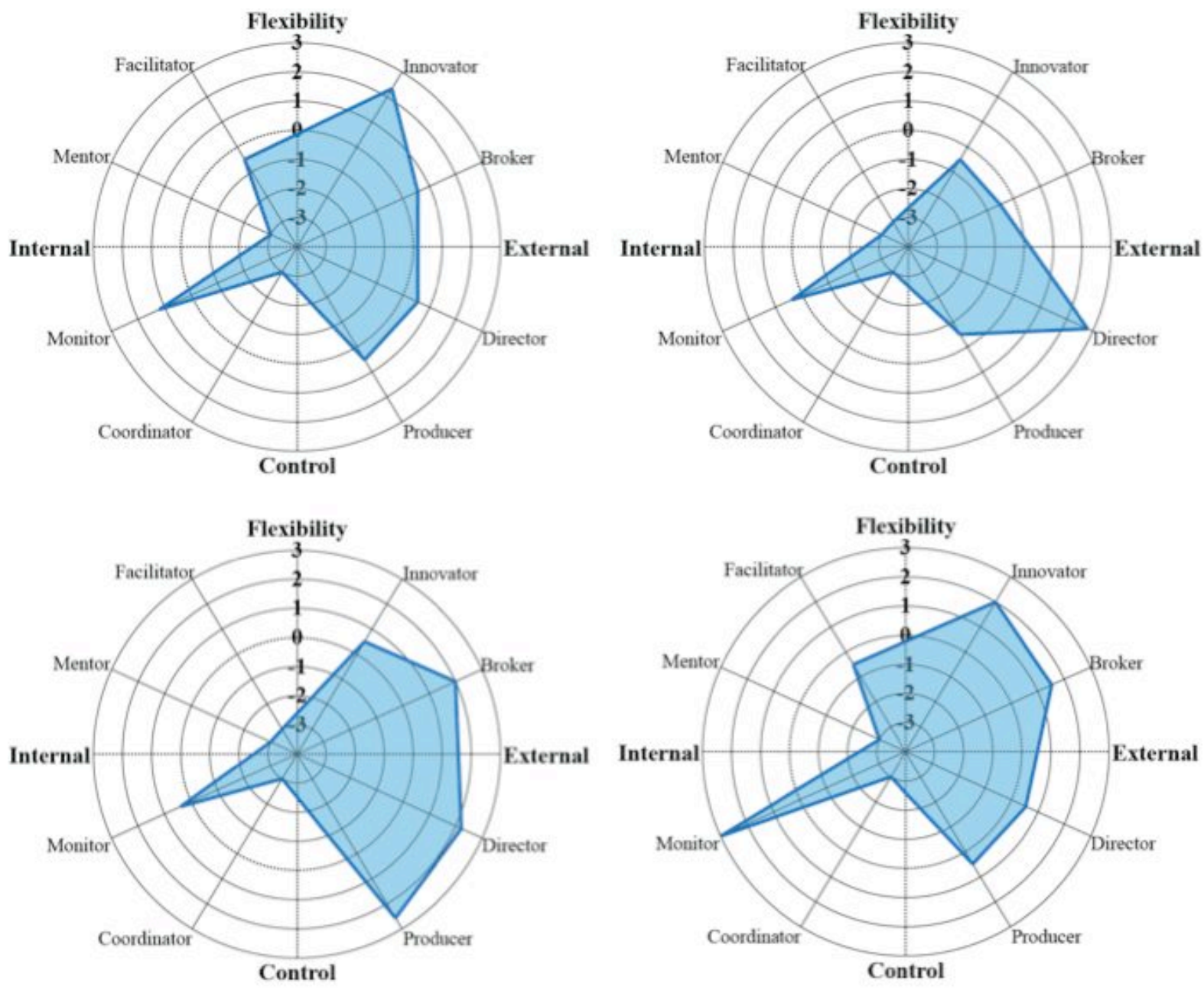

From these Makers it can be observed that there is a tendency to follow the community profile in Figure 5 . These Makers show relatively low in the relating to people roles and high in monitor and external roles.

\section{DISCUSSION}

\section{Expressions of Leadership}

When evaluating the expressions of leadership within the observed Makers it was possible to note each instance a Maker expressed a leadership trait. As seen in Figure 5, Makers tend to exemplify external leadership traits (innovator, broker, director, and producer) as well as the monitor leadership trait.

Innovator

Innovators are the "creative dreamer who sees the future, envisions innovations, and packages them in inviting ways" (Quinn, 1988). Table 5 shows the top five innovators among the participants in the study. 
Table 5. The top innovators in the observed Maker community.

\begin{tabular}{l|c|c|c|c|c|c|c|c}
\hline & Broker & Innovator & Coordinator & Monitor & Director & Producer & Facilitator & Mentor \\
\hline Samantha & 0.5 & 2.3 & -3 & 1.2 & 0.5 & 0.5 & -0.5 & -3 \\
\hline Ruben & -0.5 & 2 & -3 & 2.3 & 2.5 & 1.2 & -3 & -3 \\
\hline Trisha & 1.6 & 2 & -3 & 3 & 0.5 & 0.5 & -0.5 & -3 \\
\hline Jenna & 1.6 & 1.6 & -0.5 & 1.2 & 2.3 & 1.2 & -3 & -3 \\
\hline Matt & -3 & 1.6 & -3 & -3 & 2 & 1.2 & -3 & -3 \\
\hline
\end{tabular}

As can be seen with the Makers listed, these individuals tend to branch out and adapt to the situation within the collaboration process. Ruben, identified as an entrepreneur with an engineering background, this involved adapting to a target customer base of people who live off of the electricity grid: "So these are like for people who are off grids." Innovators recognize problems and actively seek improvements (Zafft et al., 2009). Trisha, a leader of a start-up project on Kickstarter, noticed that existing virtual reality headsets "put a little tiny display just inches away from your eyes and that's usually very problematic; it's difficult to get it aligned correctly and it can cause headaches. Some people get dizzy and sick." Her team worked around this by using projecting images out from the user utilizing augmented reality technology. By innovating, Makers are able to solve problems in unique and creative ways. Samantha, a Maker with a background in electrical engineering, designed circuitry around an existing sound card and oximeter sensor to achieve the desired functionality for her project. She integrated off-the-shelf components together in new ways to achieve her project goals. All Makers exhibited a high rank for innovative qualities.

\section{Monitor}

Monitors are "expected to know what is going on in the unit...to see if the unit is meeting its quotas" (Quinn, 1988). They are to clarify policies, expect accurate work, control projects, monitors progress, and develop measures (Zafft et al., 2009). Table 6 shows the five Makers who most strongly embodied monitor traits among those observed.

Table 6. The top monitors in the observed Maker community

\begin{tabular}{l|c|c|c|c|c|c|c|c}
\hline & Broker & Innovator & Coordinator & Monitor & Director & Producer & Facilitator & Mentor \\
\hline Trisha & 1.6 & 2 & -3 & 3 & 0.5 & 0.5 & -0.5 & -3 \\
\hline Carlos & 0.5 & 1.6 & -3 & 2.5 & 1.2 & 0.5 & -3 & -0.5 \\
\hline Ruben & -0.5 & 2 & -3 & 2.3 & 2.5 & 1.2 & -3 & -3 \\
\hline Cane & 1.2 & 1.6 & -3 & 2.3 & 0.5 & -0.5 & -3 & -3 \\
\hline Max & -0.5 & -0.5 & -3 & 2.3 & 2.3 & -0.5 & -3 & -0.5 \\
\hline
\end{tabular}

As a monitor, the leader pays attention to detail and reviews the project. Makers tend to reflect on the achievements of their projects. Trisha reflected upon how the new prototypes have "higher resolution graphics and a little wider field of view on the projection... and then the tracking system...is now twice as fast." Monitors also go through technical analysis and routine revision (Quinn, 1988). Cane, an entrepreneur in audio technology, went through multiple revisions of his product. In one revision, Cane stated "the original one had a switch but people were forgetting to turn it off and it was wasting the battery." Because of this issue, Cane's group modified the device to automatically turn off and on when different devices were plugged in. A monitor must also know how to reduce information overload and focus on what the team should be doing (Quinn et al., 1990). Ruben said that the "design is solid" and there are not any flaws in the artifact; therefore, the team was going to focus on adding more features as opposed to adjusting the design.

\section{Director}

Some Makers express the traits of a director very well. According to Quinn, a director is expected to set expectations (Quinn, 1988; Quinn et al., 1990). This can be done through a variety of methods, including goal setting, evaluating performance, setting roles, and defining the problem. Table 7 shows the five Makers who had the highest director rankings. 
Table 7. The top directors in the observed Maker community.

\begin{tabular}{l|c|c|c|c|c|r|c|c}
\hline & Broker & Innovator & Coordinator & Monitor & Director & Producer & Facilitator & Mentor \\
\hline Yin & -0.5 & -0.5 & -3 & 0.5 & 2.9 & -0.4 & -3 & -3 \\
\hline Ruben & -0.5 & 2 & -3 & 2.3 & 2.5 & 1.2 & -3 & -3 \\
\hline Heather & -3 & -3 & -3 & 2 & 2.5 & -0.5 & 2 & 1.2 \\
\hline Riya & -3 & 1.6 & -3 & 0.5 & 2.5 & 0.5 & -0.5 & -3 \\
\hline Max & -0.5 & -0.5 & -3 & 2.3 & 2.3 & -0.5 & -3 & -0.5 \\
\hline
\end{tabular}

Makers interviewed were able to articulate their design process and project performances very well. As directors, Makers set goals for their artifacts. Yin, a biochemical research scientist, designs jewelry with the purpose of sparking "communication and to educate" to create a "public awareness and connection with science." Directors also set roles and manage projects. Heather, a student who participated in an extracurricular design program, describes how within a project she assisted in proposing, "Everybody had their own unique individual parts." Defining problems is an important part of being a director. Max, a machinist, defines the problem statement of his company as "getting machines in the hands of everyday people... [and wanting] it to be the price of a printer, something you can justify having at home." In summary, it becomes apparent that setting milestones and expectations is an important part of the Makers' design process.

\section{Producer}

Qualities of a producer include determination, focused, motivated, high energy, and having personal drive (Quinn, 1988). Makers who best fit the producer role are listed in Table 8.

Table 8. The top producers in the observed Maker community

\begin{tabular}{l|c|c|c|c|c|c|c|c}
\hline & Broker & Innovator & Coordinator & Monitor & Director & Producer & Facilitator & Mentor \\
\hline Stephen & 2 & 0.5 & -3 & 0.5 & 2.3 & 2.5 & -3 & -3 \\
\hline Pam & -3 & -3 & -3 & 2 & -3 & 2 & -3 & 1.2 \\
\hline Mark & -3 & 1.2 & -3 & -0.5 & 2 & 1.6 & -3 & 0.5 \\
\hline Ruben & -0.5 & 2 & -3 & 2.3 & 2.5 & 1.2 & -3 & -3 \\
\hline Jenna & 1.6 & 1.6 & -0.5 & 1.2 & 2.3 & 1.2 & -3 & -3 \\
\hline
\end{tabular}

Makers express this drive in their conviction to their projects. Stephen, an art professor who makes his own instruments, describes himself as "a person who's really interested in my world" of audio and music. Producers are motivated to focus on goals that they set. Jenna, a Maker who designs her own baby clothes, aspires to "have a line of [her] own." In interviews, Makers often expressed their determination to succeed. Ruben said that he "...wanted to do something that was helpful." As producers, Makers harness the determination and drive to build and succeed in their endeavors.

Given the observed data it can be determined that Makers strongly possess an organizational community, and a drive to lead change and produce results. Makers fulfill the expectations of leaders as innovators, monitors, directors, and producers. Like the Engineer of 2020 (National Academy of Engineering, 2004) which describes aspirational attributes for engineers of the future, Makers are willing to leave the comfort zones of many to innovate. Through creative problem solving, the mentality of Makers as innovators can "allow [for] more effective leadership in the development and application of next-generation technologies to problems of the future" (National Academy of Engineering, 2004).

\section{IMPLICATIONS}

The Maker community consists of individuals with varied skill sets from artisans, entrepreneurs, to engineers. The actual spaces within which these individuals interact with one another allows for the exchange of backgrounds and knowledge to develop. The characteristics that these individuals have exemplified and their interchange of ideas and 
materials allow for cross-cultural management to be expressed. Cross-cultural management is a process of transferring modern management knowledge to a cross-cultural environment (Shanthakumari, 2013).

Culture may be seen as the collective values, beliefs, language, and behaviors (Evans et al., as cited in Hofmeister \& Parker, 2003), as well as the attitudes and actions of people in organizations (Adler, 2002). The characteristicssuch as those of innovators and knowledge brokers-that have been exemplified by Makers allow for the culture and organization of Makers to collectively work through one another. These collective values and actions are exemplified by Makers specifically because the Maker culture and environment leands itself to collaboration often found in organizations.

Schein (1992) said that the study of leadership can be illuminated by the analysis of culture because organizational culture is the result of company founders, leaders of movements, institution builders, and social architects (Nguyen \& Umemoto, 2009). This particular study produced criteria in which Makers aligned with certain leadership characteristics and within this context exemplify organizational frameworks within collaboration. These leaders have the ability to strengthen the community or Makers and allow individuals at different levels to work within one another in strengthening this organization of tinkerers. Schein (1992) also pointed out that cultures, in turn, create the next generation of leaders.

Complex interactions between members in an organization based on the members' different historical experiences can lead culture into another direction (Nguyen \& Umemoto, 2009). As to the Makers organization expands along different pathways, there is a resulting increase in the leader interaction and member contributions with produces additional changers and/or improvement.

Looking at the influence of leadership on culture, Adler (2002) emphasized the influence of manager's beliefs, attitudes, and values on employees' behavior (Nguyen \& Umemoto, 2009). Figure 7(a) is an example of the ways in which this can be applied to the context of managers and employees.

Figure 7. (a) Influence of manager's values, beliefs, and attitudes on employees' behavior (Adapted from Adler (2002)); (b) Influence of Maker Leader' values, beliefs and attitudes on Maker's behavior.

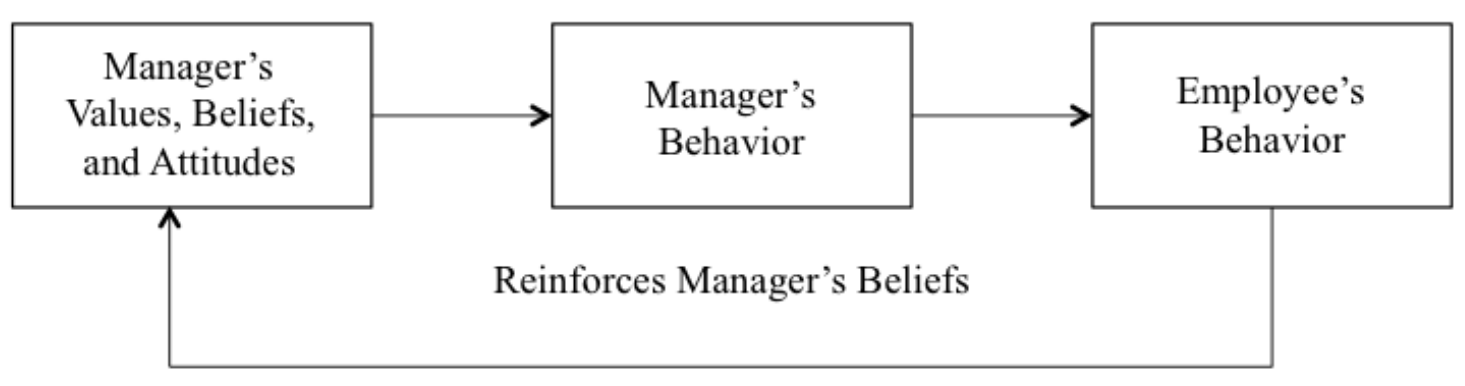

(a)

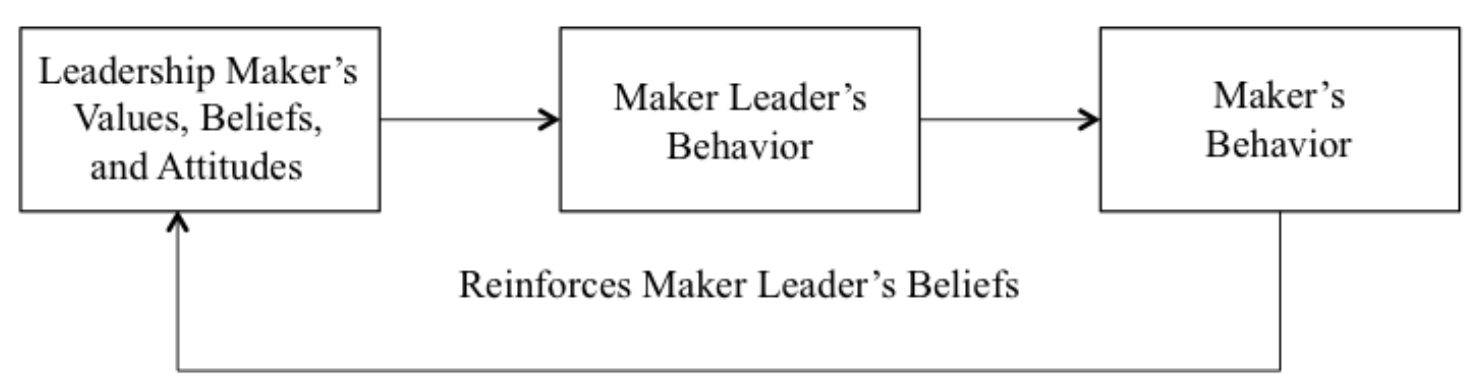

(b) 
Figure 7(b) is an example of the ways in which leaders within the Maker community can influence the community as a whole. These leaders have the ability to produce effective cultural change within the organizational community in offering new methods in learning, different expertise, and different cultural backgrounds. Organizational knowledge is the development of the members' capability in an organization "to draw distinctions in the process of carrying out their work, in particular concrete contexts, by enacting sets of generalizations whose application depends on historically evolved collective understandings" (Tsoukas \& Vladimirou, 2005, p. 128). Harris (2004) recognized that leadership is concerned with not only managing cultural differences, but also with finding ways to foster cultural synergy, which is described as a dynamic process involving adapting, learning, and creating an integrated solution.

Cross-cultural knowledge management is composed of a series of practices to recognize cultural differences, using awareness and understanding of cultural differences to develop a new culture adept at adjusting to new cultural environments. This new culture improves and enhances knowledge management activities (Nguyen, Umemoto, \& Medeni, 2007). This new culture of Making and the organization it is developing within the community of Makers allows for information to be shared and processed in different manner.

Figure 8. A theoretical model of cross-cultural knowledge management (Nguyen \& Umemoto, 2009)

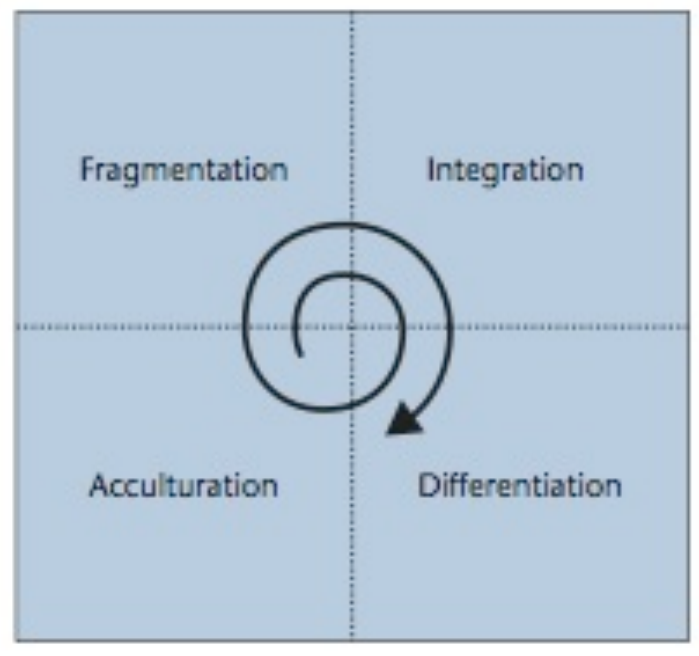

The use of this model implies continuous learning and collaboration. The different methods in which individuals within the Maker community can interact with one another allows for furthering the knowledge of the community and the skill sets. This theoretical model allows an analogous representation to be applied to the leaders within the Maker community. The theoretical model is composed of four stages: Fragmentation, Integration, Acculturation, and Differentiation (Nguyen \& Umemoto, 2009).

The first stage, fragmentation, is described as the ambiguities and uncertainties of every individual when they encounter a new culture. The ambiguities and uncertainties of this stage are explained as different interpretations of each individual. In order to avoid fragmentation, people tend to integrate into that new environment (Nguyen \& Umemoto, 2009). This has further implications in the ways in which individuals enter the Maker community through different pathways. This new culture and expertise offers different levels of understanding and collaboration.

Integration shows the intentions and efforts to get harmony and homogeneity of each individual when he or she enters a new culture. After the integration stage, each individual recognizes the existence of differences such as different cultures, backgrounds, educations, professions, and groups (Nguyen \& Umemoto, 2009). As Makers have been identified as individuals that primarily collaborate with one another, this could further imply a way in which different members within this organization begin to work with one another and how the leader chooses to actively involve others. 
Differentiation is the recognition of the separate and distinct values of cultural differences. The recognition of these differences helps every member in an organization to create a new culture, which includes values added from two or more cultures to adapt to the cross-cultural environment (Nguyen \& Umemoto, 2009). As the leaders within this context and the members begin to work with one another more there is more collaboration and understanding of how the distinct skills and expertise can be used within making.

Acculturation is used to describe these adjustments and adaptations (Nguyen \& Umemoto, 2009). As each person within this organization of Makers begins to work and understanding with one another further there is a consistent entrance or opportunity to adapt and learn different skills and jobs.

\section{CONCLUSION}

Leadership research has accentuated the important role of the organizational context of leadership and has called for more empirical studies on leadership in different contexts (Antonakis, Avoilio, \& Sivasubramaniam, 2003; Avoilio, Walumbwa, \& Weber, 2009; Porter \& McLaughlin, 2006; Tysen, Wald, \& Heidenreich, 2014). Developing this lens of studying leadership in different contexts, emergent leadership characteristics have been demonstrated within a new organizational framework of a community of Makers. As this Maker community continues to expand, further leadership implications will have to be considered. This present study highlights the leadership characteristics within these Making communities and has the potential for further research surrounding infrastructure and programs being created for these leaders.

Makers are unique examples of people practicing engineering to address problems that they personally care about. The Competing Values Framework allows us to examine leadership characteristics within this group. Our findings of the nature of leadership within this group can help shape future work on how engineers are taught, how to scope educational experiences for makers and engineers, and what focus of leadership-specific educational experiences can be imagined. By applying a cross-cultural perspective, we can extend the insights that makers express: innovator, director, producer, and monitor leadership roles to further project development of a culture aligned with associated beliefs, attitudes, and values as design principles. As we educate the makers and engineers of the future, we must keep this important aspect at the forefront of our thinking.

\section{ACKNOWLEDGEMENT}

This material is based upon work supported by the National Science Foundation under Grant No. 1329321. The authors also gratefully acknowledge the participants in this study.

\section{REFERENCES}

Adler, N. J. (2002). International dimensions of organizational behavior (4th ed.). Cincinnati, OH: South-Western.

American Society for Engineering Education. (2016). Envisioning the future of the maker movement: Summit report (Summit Report). Washington, D.C.

Antonakis, J., Avoilio, B. J., \& Sivasubramaniam, N. (2003). Context and leadership: An examination of the nine-factor fullrange leadership theory using the multifactor leadership questionnaire. Leadership Quarterly, 14, 261-295.

Avoilio, B. J., Walumbwa, F. O., \& Weber, T. J. (2009). Leadership: Current theories, research, and future directions. Annual Review of Psychology, 60, 421-449.

Bazeley, P., \& Richards, L. (2000). The NVivo qualitative project book. Thousand Oaks, CA: Sage.

Belasen, A. T., \& Frank, N. (2008). Competing values leadership: Quadrant roles and personality traits. Leadership \& Organization Development Journal, 29(2), 127-143.

Belasen, A. T., \& Ruger, R. (2007). Building a competency-based MBA from the ground up: Curriculum design and program delivery. In Academy of Management Proceedings. Philadelphia, PA.

Buenger, V., Daft, R., Conlon, E., \& Austin, J. (1996). Competing values in organizations: Contextual influences and structural consequences. Organization Science, 7(5), 557-576.

Cameron, K. S., \& Quinn, R. (2006). Diagnosing and changing organizational culture: Based on the Competing Values Framework. San Francisco, CA: Jossey-Bass.

Cameron, K. S., Quinn, R. E., DeGraff, J., \& Thakor, A. V. (2014). Competing values leadership. Edward Elgar Publishing.

Dougherty, D. (2012). The Maker Movement. Innovations, 7(3), 11-14. 
Douglas, E., Jordan, S., Lande, M., \& Bumbaco, A. (2015). Artifact elicitation as a method of qualitative inquiry in engineering education (pp. 26.235.1-26.235.10). ASEE Conferences. http://doi.org/10.18260/p.23574

Erdogan, B., Liden, R. C., \& Kraimer, M. L. (2006). Justice and leader-member exchange: The moderating role of organizational culture. The Academy of Management Journal, 49(2), 395-406.

Foster, C. H., Dickens, M., Jordan, S., \& Lande, M. (2015). Learning from Toy Makers in the Field to Inform Teaching Engineering Design in the Classroom. In Proceedings of the American Society for Engineering Education (ASEE) Annual Conference and Exposition (pp. 26.1070.1-26.1070.18). Seattle, WA: ASEE Conferences. http://doi.org/10.18260/p.24407

Foster, C. H., Lande, M., \& Jordan, S. (2014). An ethos of sharing in the Maker community. In Proceedings of the American Society for Engineering Education (ASEE) Annual Conference and Exposition. Indianapolis, IN.

Foster, C. H., Wigner, A., Lande, M., \& Jordan, S. (2015). Welcome to the Maker movement: parallel education pathways of adult Makers. In Proceedings of the American Society for Engineering Education (ASEE) Annual Conference and Exposition (pp. 26.1716.1-26.1716.18). Seattle, WA: ASEE Conferences. http://doi.org/10.18260/p.25052

Frontiera, J. (2010). Leadership and organizational culture transformation in professional sport. Journal of Leadership \& Organizational Studies, 17(1), 71-86.

Halverson, E. R., \& Sheridan, K. (2014). The Maker Movement in Education. Harvard Educational Review, 84(4), $495-504$.

Harper, D. (2002). Talking about pictures: a case for photo elicitation. Visual Studies, 17(1), 13-26.

Harris, R. P. (2004). European leadership in cultural synergy. European Business Review, 16(4), 358-380.

Hartnell, C. A., Ou, A. Y., \& Kinicki, A. (2011). Organizational culture and organizational effectiveness: a meta-analytic investigation of the competing values framework's theoretical suppositions. Journal of Applied Psychology, 96(4), 677.

Heiman, A., Lande, M., \& Jordan, S. (2015). What is Making? What is Engineering? In Proceedings of the American Society for Engineering Education (ASEE) Annual Conference and Exposition (pp. 26.1726.1-26.1726.8). Seattle, WA: ASEE Conferences. http://doi.org/10.18260/p.25062

Houghton, J. D., Carnes, A., \& Ellison, C. N. (2014). A cross-cultural examination of self-leadership: Testing for measurement invariance across four cultures. Journal of Leadership \& Organizational Studies, 21(4), 414-430.

Jordan, S., \& Lande, M. (2014). Might Young Makers be the engineers of the future? In Proceedings of the IEEE Frontiers in Education (FIE) Conference. Madrid, Spain. http://doi.org/10.1109/FIE.2014.7044218

Jordan, S., \& Lande, M. (2015). Is the engineer of 2035 a Maker? In Proceedings of the IEEE Frontiers in Education (FIE) Conference. El Paso, TX.

Jordan, S., \& Lande, M. (2016). Additive innovation in design thinking and making. International Journal of Engineering Education, 32(3).

Lande, M., \& Jordan, S. (2014). Methods for examining the educational pathways of adult Makers. In Proceedings of the American Society for Engineering Education (ASEE) Annual Conference and Exposition. Indianapolis, IN.

Lande, M., Jordan, S., \& Nelson, J. (2013). Defining Makers making: Emergent practice and emergent meaning. In Proceedings of the American Society for Engineering Education (ASEE) Annual Conference \& Exposition. Atlanta, GA.

Morley, K. M., Pawley, A. L., Jordan, S. S., \& Adams, R. (2011). Gender and engineering: Photo elicitation as a method of inquiry. In Proceedings of the American Society for Engineering Education (ASEE) Annual Conference \& Exposition. Vancouver, British Columbia.

National Academy of Engineering. (2004). The engineer of 2020: Visions of engineering in the new century. Washington, D.C.: National Academies Press.

Nguyen, N. T. B., \& Umemoto, K. (2009). Understanding Leadership For Cross-Cultural Knowledge Management. Journal of Leadership Studies, 2(4), 23-35. http://doi.org/10.1002/jls.20078

Nguyen, N. T. B., Umemoto, K., \& Medeni, T. (2007). Towards a theoretical model of cross-cultural knowledge management. Journal of Knowledge, Culture, and Change Management, 7(9), 33-40.

Oplinger, J., Heiman, A., Dickens, M., Foster, C. H., Jordan, S., \& Lande, M. (2014). Making and engineering: Understanding similarities and differences. In Proceedings of the American Society for Engineering Education (ASEE) Annual Conference and Exposition. Indianapolis, IN.

Porter, L. W., \& McLaughlin, G. B. (2006). Leadership and the organizational context: Like the weather? Leadership Quarterly, $17,559-576$.

Quinn, R. E. (1988). Beyond rational management: Mastering the paradoxes and competing demands of high performance. Jossey-Bass. Retrieved from http://psycnet.apa.org/psycinfo/1988-97332-000

Quinn, R. E., Hildebrandt, H. W., Rogers, P., \& Thompson, M. P. (1990). Effective management communication: a competing values framework (Working Paper No. 637R). Ann Arbor, MI: University of Michigan. Retrieved from http://deepblue.lib.umich.edu/handle/2027.42/35994

Quinn, R. E., \& Rohrbaugh, J. (1983). A spatial model of effectiveness criteria: Towards a competing values approach to organizational analysis. Management Science, 29(3), 363-377.

Schein, E. H. (1990). Organizational culture. American Psychologist, 45(2), 109-119.

Schein, E. H. (1992). Organizational Culture and Leadership (2nd ed.). San Francisco, CA: Jossey-Bass.

Sendelbach, N. B. (1993). The competing values framework for management training and development: A tool for understanding complex issues and tasks. Human Resource Management, 32(1), 75-99. 
TechShop. (2015). TechShop is America's 1st Nationwide Open-Access Public Workshop -- What Do You Want To Make at TechShop? Retrieved December 15, 2015, from http://www.techshop.ws/

Tong, Y. K., \& Arvey, R. D. (2015). Managing complexity via the Competing Values Framework. Journal of Management Development, 34(6), 653-673. http://doi.org/10.1108/JMD-04-2014-0029

Tsoukas, H., \& Vladimirou, E. (2005). What is organizational knowledge? In S. Listtle \& T. Ray (Eds.), Managing knowledge: An essential reader (pp. 85-106). London: Sage Publications.

Tweney, D. (2009, March 29). DIY Freaks Flock to "Hacker Spaces" Worldwide. Retrieved December 15, 2015, from http://www.wired.com/2009/03/hackerspaces/

Tysen, A. K., Wald, A., \& Heidenreich, S. (2014). Leadership in the contet of temporary organizations: A study on the effects of transactional and transformational leadership on followers' commitment in projects. Journal of Leadership \& Organizational Studies, 21(4), 376-393.

Yang, J. T. (2007). Knowledge sharing: Investigating appropriate leadership roles and collaborative culture. Tourism Management, 28(2), 530-543.

Zafft, C. R., Adams, S. G., \& Matkin, G. S. (2009). Measuring Leadership in Self-Managed Teams Using the Competing Values Framework. Journal of Engineering Education, 98(3), 273-282. 